\title{
Collaboration in scholarly communication \\ Opportunities to normalize open access
}

A

most librarians are well aware, open access and scholarly communication have been and will continue to be hot button issues. But what is a librarian's role within the library? What about out in the greater world of scholarly communication? How do we ensure the changes we wish to see? To answer these, we must look at scholarly communication from a more holistic approach. It cannot simply be the job or responsibility of one group, or, even worse, one person on a campus. Scholarly communication is a multifaceted issue that should be addressed through education, outreach, recognition, and fiscal support. With so many lingering questions and doubts from faculty and students, librarians must continue to educate, collaborate, and highlight in ways we have not tried before. At the University of North Texas (UNT) Libraries, through collaboration and communication, we have made great progress toward reaching these goals.

\section{Outreach and education-author's rights}

Assisting authors in retaining their rights can open a door to a discussion about the larger landscape of scholarly communication, and provide an opportunity for librarians to address any misconceptions authors might have about open access or publishing in general. A study ${ }^{1}$ shows that while scholars and researchers are aware of the existence of open access, their level of in-depth knowledge is lacking. A different study that uses the Unified Theory of Acceptance and Use of Technology shows that a deeper understanding of open access and scholarly communication can enhance the acceptance and adoption of open access. ${ }^{2}$ This is an excellent opportunity for librarians to step in. Educating faculty about author's rights in a nonthreatening manner is one way to provide necessary education for authors, scholars, and researchers. Authors often seek to retain their rights, but do not know how, or have misconceptions about rights they can retain. ${ }^{3}$

One-on-one consultations with a scholarly communication or copyright librarian, or through larger educational opportunities like workshops, are ways we seek to educate researchers. Scholarly communication offices do not always have direct access to faculty or students who are publishing in the way that subject librarians might have personal connections offering an opportunity for collaboration. Working with subject librarians can provide scholarly communication

Allyson Rodriguez is electronic resources librarian at the University of North Texas, email: allyson.rodriguez@ unt.edu

๑ 2017 Allyson Rodriguez 
librarians personal and trusted connections that might otherwise be missing or limited.

To better facilitate these collaborations, UNT Libraries formed the Scholarly Communication Transformation Workgroup, which meets two times per month to discuss these and related issues. The workgroup brings together representatives from the Scholarly Communications office; the Digital Libraries division, where our institutional repository is housed; the Collection Management division; and Public Services, where our subject librarians live. Through these regular meetings, we keep each other up-to-date on our own projects, discuss challenges we face, and seek opportunities for collaboration.

\section{Outreach and education-using open access}

Often scholarly communication librarians feel separated from other areas of the libraries, but this should not be the case. Collaborating with all types of librarians can have incredible impact and offer insight you might otherwise miss. For example, while librarians like to think that concerns about the quality of open access resources are limited, they do still exist. ${ }^{4}$ Concerns about the quality of open access can be addressed through education and exposure. Questions regarding the lack of peer-review or other quality concerns are often fielded by subject or liaison librarians and can be addressed through those personal relationships. Scholarly communication and subject librarians should communicate often about these concerns to make sure all parties are informed.

Collection development librarians provide access to high-quality open access resources through the library catalog, offering their stamp of approval. They use expert information literacy skills to evaluate and weed out questionable sources that might give open access a bad name. Once these items are in the catalog, presenting them as any other resource is essential. By not highlighting whether a resource is open access, librarians give faculty and students the opportunity to judge a resource on its educational and research value and lessen any preconceived notions they might have about open access, or other methods of scholarly communication.

Exposing faculty and students to open access resources within the catalog can provide opportunities for open access to become a normal part of their research and educational experiences and increase the use and acceptance of open access resources. However, adding open access resources to the library catalog should not fall solely on the shoulders of collection development librarians, but act as another point for collaboration. Collection development librarians take suggestions from faculty, librarians, staff, and others to add open access resources to the library catalog. Throughout this process there is a string of communication-why a resource is included, or not included; how open a resource is; questions to the subject librarian about the quality or relevancy of content; sharing of new open access resources discovered, and thus opportunities for teachable moments.

\section{Outreach and education-resource purchasing decisions}

To further educate researchers on the everevolving landscape of scholarly communication, collection development and subject librarians can provide insight and seize teachable moments regarding purchased or subscribed library resources. If, during negotiations or while investigating requested library resources, particularly undesirable terms are revealed, take time to share these concerns with the requesting faculty member or researchers. Faculty members can be understanding when restrictive licensing terms, or outrageous fees, are shared with them. Showing how extremely restrictive licensing terms can impact their potential use of the resource can also have a great impact.

At the UNT Libraries, we found it beneficial to have a concerned faculty member or two involved during a phone call or 
presentation with a vendor. Allowing the faculty member to ask the vendor questions and hearing the vendor's reactions can further illuminate the current scholarly communication landscape. There is no need to be secretive or opaque about the processes used to acquire scholarly resources. This way, stakeholders understand the process and reasons behind purchasing decisions, leading to greater trust and understanding when difficult decisions must be made and subtly building the case for open access.

\section{Highlighting and celebrating}

Beyond education and outreach it is essential to recognize those already supporting and helping to improve the dissemination of scholarly research. Incentivizing publication in open access through recognition is seen as a major facilitating factor in the widespread use and acceptance of open access. ${ }^{5}$ Positive reinforcement can do wonders to encourage both those already participating and those reluctant to join: It can be accomplished through a reward system for publishing open access, ${ }^{6}$ acceptance of open access publishing in promotion and tenure decisions, ${ }^{7}$ and is seen through highlighting contributors and their contributions to the institutional repository.

Repository and scholarly communication librarians will be the center of these efforts. However, subject librarians and collection development librarians have an important role in celebrating faculty who publish open access or contribute to a repository. Again, subject librarians are valuable resources for reaching out to faculty. Subject librarians are typically more aware of research and publications coming from their faculty and can alert the repository librarian to any relevant research output. Surprisingly to some, collection development librarians can also have a place in these transactions.

As evidenced by the SPARC/ACRL Forum at the ALA Midwinter Meeting, more collection development departments are taking an active, or leading, role in the scholarly communication discussion. During the fo- rum, three representatives of collection development departments discussed their steps toward rethinking and integrating scholarly communication into the collections department, even positioning collection development within scholarly communication.

\section{Open access and acquisitions}

One of the most important, and most often discussed, way for libraries to support and further open access is through monetary support. It's a way to "Put your money where your mouth is." However, this is a complicated issue to address within many institutions. The recession experienced in recent years caused library budgets to contract, often leading to reduced personnel and drastically cut materials budgets. ${ }^{8}$ Finding ways to financially support efforts from a collections budget that might otherwise come to a library for free can be a difficult case to make, especially in light of faculty requests, the rising cost of resources, the need to be good stewards of state, federal, or student money, and many other internal and external factors.

To counter these questions and concerns, it is best to view open access and paid-for open access initiatives as another vendor category. By viewing open access as another option to "purchase" content, collection development librarians can evaluate the resources as they would a normal product. Even if a resource is "free," there are other considerations to take into account when deciding whether to include a resource in the library catalog.

At the UNT Libraries, we use a rubric with areas such as authority of the author or publisher, the objectivity, currency, and relevancy of the information; the functionality of the resource or additional software requirements; and the quality of the content or review process to evaluate the resource. We similarly evaluate paid resources with a rubric, but cost, licensing concerns, and vendor interactions (e.g., promptness of responses, clarity of information provided, etc.) are included. The addition of a third 
vendor category is available through the fiscal support of open access initiatives. Again, these initiatives should be evaluated using the same criteria as the freely available and paid-for resources with the addition of considerations like the objective of the initiative, possible author fees, additional benefits (e.g., a seat on a voting board, early access to materials, discounts for print versions, etc.). Resources from all three of these vendor categories move through the same workflows, are considered from the same budget, and are evaluated similarly. If a resource meets our requirements for inclusion and the budget is available at that time, then it is included, supported, subscribed to, or purchased.

Vigorously reviewing the quality of the content, gauging the vendor interaction and communications, and considering other evaluation criteria provides support for making financial decisions. Inviting scholarly communication and subject librarians into these purchasing conversations, both as expert evaluators and as requesting entities, is another opportunity to combine forces for the best outcome. The ability to justify the funds after such thorough evaluation becomes a much easier and clearer process. A fortuitous benefit of putting open access resources through a normal acquisition process is the normalization of open access, seamlessly integrating open access into the library and research of an institution.

\section{Conclusion}

Scholarly communication and the open access movement have come a long way in recent years; however, there is still room for improvement. Open access must become a "normal" part of the academic lifestyle. To accomplish this, librarians from scholarly communication, public services, technical services, and more must work together to address lingering questions and concerns. Meeting regularly, sharing information as well as tasks, breaking down siloes, collaborating, and thinking creatively about obstacles can greatly increase the opportunities for success.
Through education on everything from copyright and author's rights issues to library licensing concerns; outreach to faculty researchers and students; recognition of proponents; and financial support, libraries and librarians can normalize open access and realize the change they wish to see in scholarly communication.

\section{Notes}

1. Jingfeng Xia, "A longitudinal study of scholars attitudes and behaviors toward open-access journal publishing," Journal of the American Society for Information Science and Technology, 2010, https://doi. org/10.1002/asi.21283.

2. Frankwell W. Dulle and M. K. MinishiMajanja, "The suitability of the Unified Theory of Acceptance and Use of Technology (UTAUT) model in open access adoption studies," Information Development 27, no. 1 (2011): 32-45, https://doi. org/10.1177/0266666910385375.

3. Kristine K. Fowler, "Mathematicians' Views on Current Publishing Issues: A Survey of Researchers," Issues in Science and Technology Librarianship, Fall 2011, https:// doi.org/10.5062/F4QN64NM.

4. Robert Tomaszewski, Sonia Poulin, and Karen I. Macdonald, "Publishing in Discipline-Specific Open Access Journals: Opportunities and Outreach for Librarians," The Journal of Academic Librarianship 39, no. 1 (2013): 61-66, https://doi.org/10.1016/j. acalib.2012.11.008.

5. Dulle and Minishi-Majanja, "The suitability of the Unified Theory of Acceptance and Use of Technology (UTAUT) model in open access adoption studies," https://doi. org/10.5062/F4QN64NM.

6. Ibid.

7. Xia, "A longitudinal study of scholars attitudes and behaviors toward open-access journal publishing," https://doi.org/10.1002/asi.21283.

8. Charles I. Guarria and Zhonghong Wang, "The Economic Crisis and its Effect on Libraries," New Library World 112, no. 5 (2011): 199-2-14, https://doi. org/10.1108/03074801111136248. 